\title{
Simulation research on rail transit traction grid voltage stabilization and its energy saving effects based on BESS
}

\author{
Shili Lin*, Wenji Song, Ziping Feng \\ Guangzhou Institute of Energy Conversion, Chinese Academy of Sciences, Guangzhou, 510640, PR China
}

\begin{abstract}
In order to realize voltage stabilization and energy saving of rail transit traction supply system, a Li-ion battery energy storage system (BESS) is presented for application in the DC traction grid to reuse the braking energy of the vehicles. According to the models of traction substation, power lines and vehicles, the braking energy saved by BESS is calculated in MatLAB/Simulink, and the performances of stabling the DC grid voltage are simulated with BESS and braking resistor respectively. By comparing the simulation results, it shows that the BESS could achieve good effects of DC grid voltage stabilization not only during the braking process but also during the traction process of the vehicles. Furthermore, the BESS is tested and verified to absorb and recycle the braking energy availably; therefore, it could well meet the purposes of clean energy and green travel of rail transit.
\end{abstract}

Keywords: Rail transit, braking energy, battery energy storage system

\section{Introduction}

Rail Transit, which possesses large carrying capacity, fast speed, low emission pollution and many other advantages [1], is an ideal means of transportation for modern cities and developing quickly nowadays. At present, the traction supply system of rail transit is generally set to power-up by $750 \mathrm{~V}$ or $1500 \mathrm{~V}$ DC, and rail transit vehicles with VVVF transmission mode are used widely, instead of the old cam trimming vehicles and chopper vehicles $[2,3]$. This new kind of vehicles will convert mechanical energy to electrical energy when braking, and feed back the energy to DC traction grid. The renewable energy can be reused as traction energy by other vehicles on the same power supply interval. However, when the regenerated energy is too large to be absorbed timely, the voltage of the DC traction grid will increase fast and exceed the safety threshold voltage, causing a lot of serious security problems to traction supply system, such as damages to electrical equipments, braking failure of vehicles, and so on $[4,5]$.

In order to prevent the voltage of DC traction grid from becoming too high, a widely used approach is to install brake resistor on the vehicle or traction substation [6]. When feedback energy leads to the DC grid voltage more than the threshold limit, the brake resistor would startup to consume surplus energy and make the voltage drop to a safety level. Resistor consumption mode is easy to achieve a good effect of voltage descent; however, this approach not only results in a tremendous waste of regenerative braking energy, but also increases the ventilation and cooling energy consumption. As a result, it weakens the significance of regeneration braking and does not meet the purposes of clean energy and green travel of rail transit.

Therefore, the energy storage technology of rail transit system is studied in this paper. In connection with Guangzhou Metro Line Four, the Li-ion battery energy storage system (BESS) is researched to realize energy saving for the $1500 \mathrm{~V}$ DC traction grid. Moreover, the capacity and control strategy of BESS are designed and simulated by MatLAB/Simulink, aiming to test and verify the system's

\footnotetext{
* Manuscript received June 14, 2014; revised July 23, 2014.

Corresponding author: Shili Lin; Tel.: +86-020-87059478; E-mail address: linsl@ms.giec.ac.cn.

doi: $10.12720 /$ sgce.3.4.431-436
} 
performance of stabilizing the DC grid voltage during the braking and traction process.

\section{BESS of Rail Transit}

With the characteristics of large energy and instantaneous power, the braking energy feedback to DC traction grid was showed from actual measurement data that its maximum power and total energy reached up to $2.3 \mathrm{MW}$ and $9 \mathrm{kwh}$ respectively during the braking process [7]. This dual demand is a big challenge for energy storage systems. Yet with the development of battery technology in recent years, the cell capacity and power density of Li-ion battery that used to be a high energy density storage device are both stepping forward significantly. Currently, the continued charge-discharge rate of lithium battery is reaching a level of $6 \mathrm{C}$. Moreover, some high performance one could even bear a current up to $20 \mathrm{C}$ in a short time. Therefore, applying BESS to recycle braking energy is a good choice for rail transit power supply system that could satisfy the requirements of capacity and power simultaneously.

The architecture of BESS of rail transit is shown in Fig. 1. In order to get a better control performance of charging and discharging for Li-ion battery pack, which is composed of many cells by the way of series and parallel, a bidirectional DC/DC converter is served as an interface unit to connect the Li-ion battery pack and DC traction grid. By controlling the switching state of the bidirectional DC/DC converter, the batteries will be charged at the time that the DC grid voltage is too high, while discharge to DC traction grid as voltage support when a vehicle starts or accelerates. Via the storage and release of braking energy, BESS could ensure that the DC traction grid works in an appropriate range of voltage and achieve the effect of energy conservation.

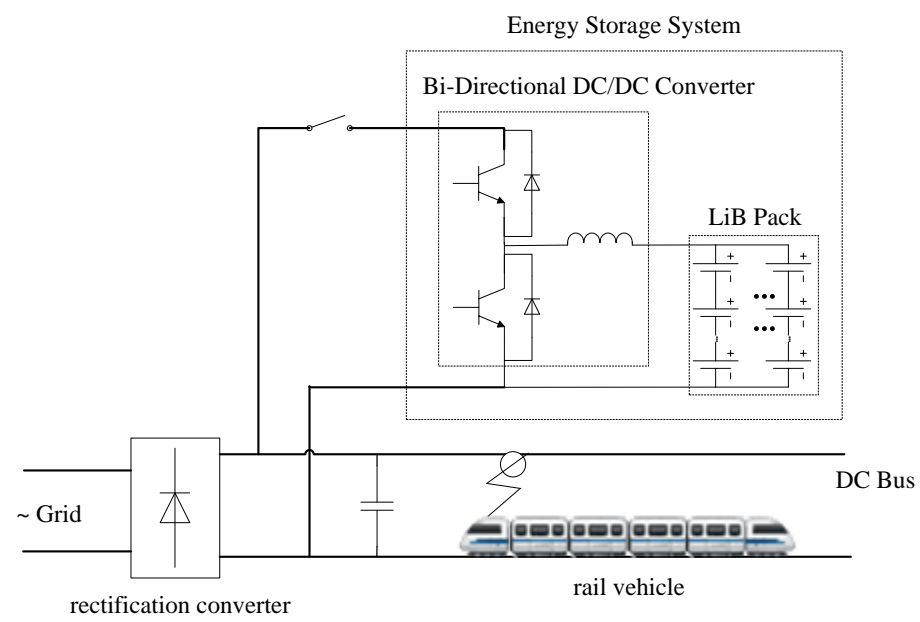

Fig. 1. Li-ion battery energy storage system of rail transit.

\section{Models of Traction Supply System}

The traction and braking of rail transit vehicles will lead to voltage fluctuations of DC traction grid. Especially in the cases that braking energy is not absorbed completely by other vehicles, as well as that several vehicles on the same interval are all in the state of running, there will be a significant change of the voltage that would seriously affect the electric power quality and power supply safety. In rail transit traction supply system, the DC grid voltage is related to traction substations, power lines and rail transit vehicles, so the models of these parts will be discussed and set up by MatLAB/Simulink as following.

\subsection{Model of traction substation}

The $1500 \mathrm{~V}$ DC traction supply system of rail transit takes advantage of 12 or 24 pulse wave rectifier which converts the $1180 \mathrm{~V}$ AC output from buck rectifier substation to direct current [8]. According to Thevenin equivalence principle and ideal external characteristic of uncontrolled rectifier circuit, the 
traction substation is modeled by a series circuit including an ideal voltage source $\mathrm{U}_{\mathrm{s}}$, an internal resistance $R_{e q}$ and a diode. Combined with the rated capacity and working voltage, the traction substation could be expressed by the simplified formulae shown as Eq. (1):

$$
\left\{\begin{array}{l}
U_{s}=U_{d 0} \\
R_{e q}=\left(U_{d 0}-U_{d N}\right) U_{d N} / P_{s} /
\end{array}\right.
$$

where $U_{d 0}$ is the open circuit voltage after rectification; $U_{d N}$ is the rated voltage of DC traction grid; $P_{s}$ is the rated capacity of traction substation.

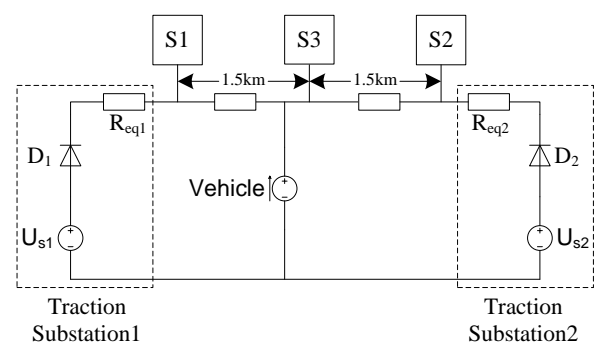

Fig. 2. Model of traction power supply system.

The bilateral power supply mode is adopted mainly by most power supply systems of rail transit [9]. Under normal conditions, the vehicle is powered by the co-operation of two traction substations connected to the driving interval. Therefore, ignoring the effect of current flow of any other interval, the power supply system could simply be taken for analysis by only one interval. The typical bilateral power supply mode usually includes two traction substations and three railway platforms, two of which are respectively at the same position of the two substations apart about $3 \mathrm{~km}$ and another is just in the middle, that is to say, the distances from the third one to the other two are both $1.5 \mathrm{~km}$. The simplified circuit is shown in Fig. 2. Note that the power a vehicle needs to operate is originated from two traction substations, and the proportion a substation should provide is decided by its distance to the vehicle. The shorter the distance is, the greater the substation should commit, and vice versa.

\subsection{Model of power lines}

With the movement of the vehicle, the line resistance between the vehicle and the substation is varying all the time because of the changing distance. Thus, the power line could be considered as a time-varying network and the line resistance can be determined by the changes of the distance. As the line resistance is a function of the distance, the model could be set up by a voltage source in MatLAB, which is shown in Fig. 3 (a). According to the unit resistance values of power supply line and reflux line, the corresponding models can be got by altering the value of gain in the model.

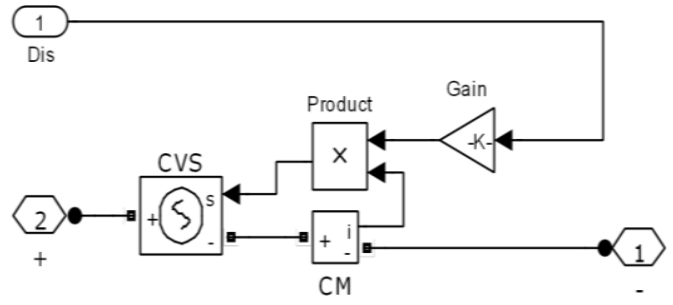

(a)

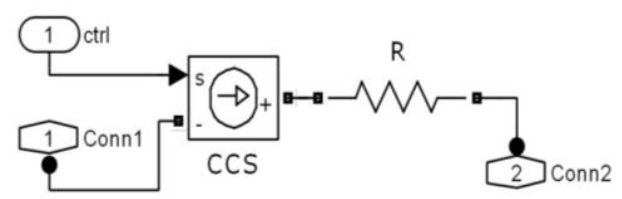

(b)

Fig. 3. Models in Simulink: (a) the line impedance and (b) the vehicle.

\subsection{Model of vehicles}

Currently, the rail vehicles usually use VVVF converters to execute traction and braking, so the realtime power of a vehicle is determined only by the traction and braking characteristics of the vehicle itself, 
whereas irrelevant with the DC grid voltage. Therefore, the vehicle could be modeled as Fig. 3 (b) by a controlled current source, which simulates the operation characteristic of the vehicle. In addition, the parameter of its control signal could be valued by the quotient of instantaneous power and terminal voltage of the vehicle.

\section{Simulation and Performance Comparison}

Guangzhou Metro Line Four, taken as the research object in this paper, is supplied by $1500 \mathrm{~V}$ DC grid, of which the voltage fluctuation range is from $1000 \mathrm{~V}$ to $1800 \mathrm{~V}$ and open circuit voltage is $1669 \mathrm{~V}$. The unit resistances of conduct rail and reflow rail are $0.008 \Omega / \mathrm{km}$ and $0.0137 \Omega / \mathrm{km}$, respectively; meanwhile, the traction and braking characteristic curves of the vehicles used in Line Four are shown in Fig. 4.
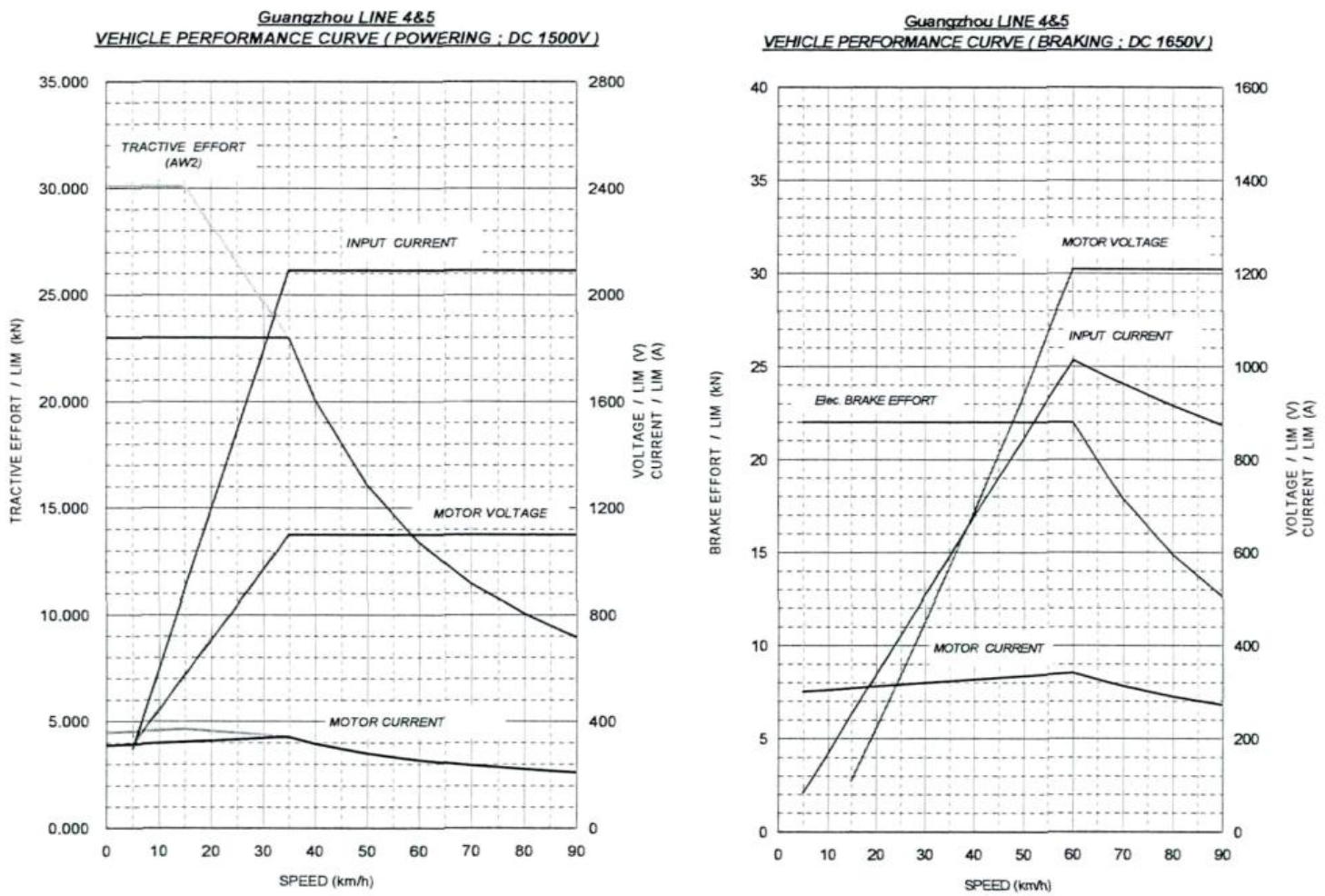

Fig. 4. Traction and braking characteristics of the vehicles of Guangzhou metro line four.

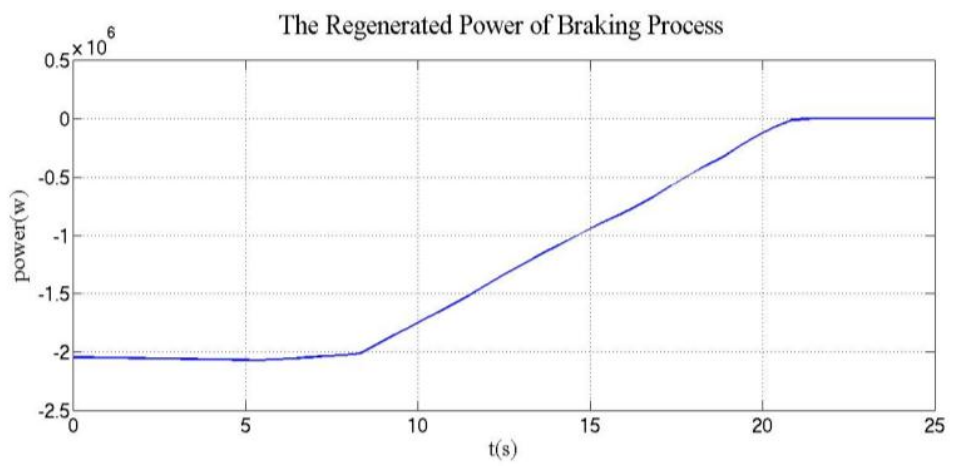

Fig. 5. Regenerated power during braking process.

Assume that there was only one vehicle braking on the power supply interval. The regenerated power during the whole braking process is simulated in MatLAB/Simulink by the system models and the 
braking characteristic of the vehicle mentioned above, with the simulation result of a changing curve shown in Fig. 5. It can be seen that the maximum power feedback to DC traction grid during braking process is up to $2070 \mathrm{~kW}$ and the average power is $1190 \mathrm{~kW}$, while the total regenerated energy is about $8.25 \mathrm{kWh}$. The simulation result is consistent with the measured data, proving the correctness of the models of traction supply system built in this paper.

\subsection{Control Strategy and Simulation Analysis}

The energy storage component of BESS studied in this paper is Li-ion battery with parameters of $3.2 \mathrm{~V} / 60 \mathrm{Ah}$. In the range of $20 \%$ to $80 \%$ of state of charge (SOC), a battery cell could be considered to work at the platform voltage, which is a constant value of $3.2 \mathrm{~V}$. Thus, the depth of discharge (DOD) of the cell was set at $60 \%$ for a better control performance. According to these conditions, the Li-ion battery pack was designed to be composed of 216 cells in serial and then 10 sets in parallel by the constraints of capacity, power and converter efficiency, with the result that it had a total terminal voltage of $690 \mathrm{~V}$ and a peak current of 3000 A that could be able to meet the demand of storage and release.

Combined with the design parameters of BESS and the traction and braking characteristics of the vehicle, the DC grid voltage could be stabilized at an appropriate range by controlling the bidirectional DC/DC converter to store and release the braking energy. When the voltage rose up to $1750 \mathrm{~V}$ due to overabundance of braking energy, the converter started to charge the Li-ion battery pack and kept the charging status until that the voltage dropped to $1680 \mathrm{~V}$, or that the SOC of BESS reached $80 \%$. On the contrary, when it reduced to $1450 \mathrm{~V}$ during traction, the converter would be at a discharging status to provide electrical power from Li-ion battery pack to DC traction grid and switched off at the time that the voltage recovered to $1500 \mathrm{~V}$, or that the SOC of BESS was lower than $20 \%$. Based on this control strategy of the bidirectional DC/DC converter, the situations of voltage fluctuation during braking and traction process were simulated and the result was shown in Fig. 6.

Voltage of DC Grid By BESS

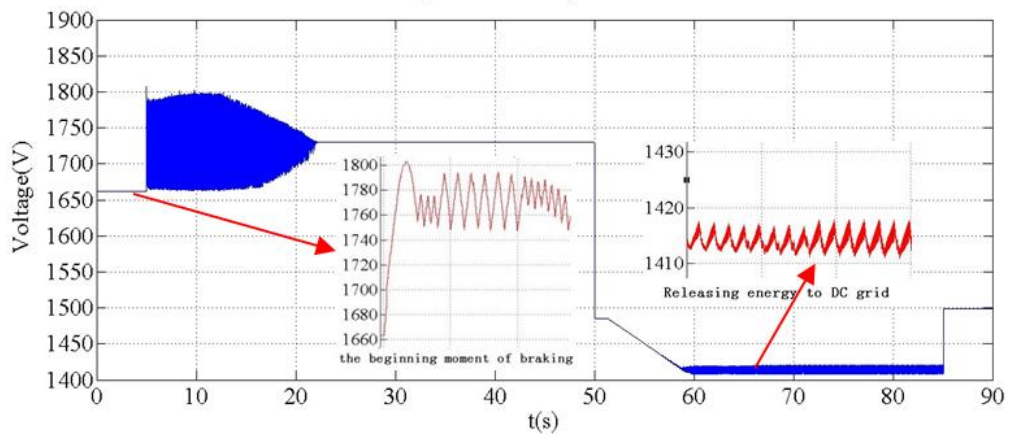

Fig. 6. Voltage of DC grid by BESS.

It can be seen from Fig. 6 that when the vehicle braked, the regenerated energy was absorbed by the BESS so that the voltage could be practically limited under $1800 \mathrm{~V}$. While there was a heavy demand of traction energy, the BESS released its storage energy to provide auxiliary energy, getting a good effect of inhibiting descent of the DC grid voltage. Moreover, according to the result calculated from simulation program, the energy stored into the BESS was about $8 \mathrm{kwh}$ during the braking process, which made the SOC of Li-ion battery pack increase by $1.9 \%$. Consequently, the BESS had used the regenerated energy effectively and got the purpose of DC grid voltage stabilization and energy saving.

\subsection{Contrast of performance}

Under the same conditions, the resistor consumption mode was simulated with a ground resistance box valued at $2.5 \Omega$, which is applying to Guangzhou Metro Line Four at present. The curve of voltage fluctuation was obtained as Fig. 7. As can be seen, the resistor consumption mode responded more quickly to the demand of suppressing an exorbitant voltage than the BESS during braking and had a 
smaller overshooting as well. The result indicated that the resistor consumption mode was better at control performance in the process of braking. However, it was unable to provide energy support so that it would lead to a large decline of the DC grid voltage during traction process. Meanwhile, the simulation results showed that the energy consumed on the braking resistor was about $8 \mathrm{kwh}$, which was not be used at all and resulting in a great waste of energy.

Based on the discussion above, it is known that the BESS could almost have the same control performance as braking resistor in stabling the DC grid voltage of rail transit. In the meantime, the braking energy could be absorbed enough and reused to support the DC traction grid during the time a vehicle accelerates. Therefore, BESS can achieve the purposes of energy saving and protect the security of rail transit power supply system, and it can be well instead of the braking resistor in rail transit.

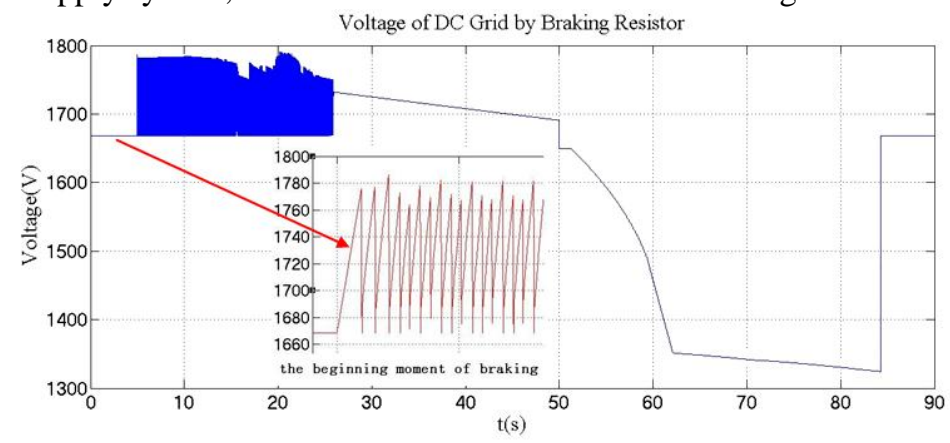

Fig. 7. Voltage of DC grid by braking resistor.

\section{Conclusions}

The models of rail transit traction supply system were established in this paper and the traction and braking process of a rail vehicle was simulated in MatLAB/Simulink. According to the results of calculating braking energy, the parameters of BESS were designed. And then it took two simulations to compare the performance of stabling the DC grid voltage respectively with BESS and braking resistor, besides, the effect of energy saving of BESS were analyzed, to provide references to the application of BESS in rail transit and the design of its structural parameters.

\section{Acknowledgements}

Foundation of Key Laboratory of Renewable Energy, Chinese Academy of Sciences (y407ja1001)

\section{References}

[1] Yang J, Li FY, Song RG, Fang Y. Review of the utilization of vehicular braking energy in urban railway transportation. Journal of the China Railway Society, 2011; 33(2):26-33.

[2] Xu AG, Xie SJ, Yao Y, Liu XB, Xiao HF, Feng JJ. Regenerating energy storage system based on ultra-capacitor for urban railway vehicles. Transactions of China Electro technical Society, 2010; 25(3):117-123.

[3] Lin SL, Song WJ, Hu JX, Feng ZP. Simulation on regenerative braking energy and utilization efficiency of rail transit vehicle. Urban Mass Transit, 2014; 5:59-63.

[4] Reza T, Razieh NF, Behzad A, Hossein IE. Energy recovery in a metro network using stationary super capacitors. In: Proc. IEEE Drive Systems and Technologies Conference, 2011:324-329.

[5] Liu BL. Analysis on energy consumption of metro train. Electric Locomotives and Mass Transit Vehicles, 2007; 30(4):65-70.

[6] Reza. T, Behzad A, Hossein IE, Razieh NF. Stationary super-capacitor energy storage system to save regenerative braking energy in a metro line. Energy Conversion and Management, 2012; 56:206-214.

[7] Li KP, Zhang ZS. Design of ground braking resistor in Guangzhou metro line 4. Electric Drive for Locomotives, 2005; 5:4346.

[8] Dong HY, Tian MX, Du BX, Zhang F. Simulation and harmonic current analysis of 24-pulse rectifier unit in metro. Chinese Journal of Power Sources, 2011; 35(5):593-594.

[9] Zhang WL, Li QZ, Liu W, Xie SF. Simulation research on energy saving scheme of metro vehicle regenerative braking. Converter Technology \& Electric Traction, 2008; 3:41-44. 